\title{
EDITOR'S INTRODUCTION: THE BOOK IN FACT AND FICTION IN PRE-MODERN ARABIC LITERATURE
}

\author{
Antonella Ghersetti \\ UNIVERSITÀ CA' FOSCARI, VENICE
}

As Johannes Pedersen stated in his seminal work: in scarcely any other culture did literary life play such a role as in Islam'. ${ }^{1}$ Speedy dissemination of books, their transmission, authentication, production, reproduction and exchange testify to an enormous activity in the ArabIslamic world. The result of these intellectual undertakings was great indeed: many Arabic scholars of the pre-modern period are famous for their prodigious output, which biographical sources reckoned in terms of pages, physical volumes and titles. According to Ibn al-Nadīm, the fourth/tenth century-scholar al-Marzubānī wrote over 38,000 pages! Books in both their concrete and intellectual sense were frequently a topic of discussion. Declarations of passionate love for books are quite common in Arabic literature, alongside literary representations of a passion for written materials - even verging on pathological attachment. The image of the personified book is also often found in the sources: it can be a trusted friend or might reveal itself as a generous teacher, always ready to inform and encourage conversation among people living in different times and places.

The study of the book as a material and intellectual item is multifaceted and covers all aspects related to book-production and their role in culture and society too. This encompasses delicate issues touching on problems of authorship; transmission of knowledge and knowledge control; the relationship between oral and written information, as well as freedom and books. Scholars have focused both on the material aspects of the book and on the great role it played as a cultural vehicle in the Arab-Muslim world. The material aspects of the Arabic book have been thoroughly investigated, mainly through a traditional bibliographic approach, whereas investigations into the book as an intellectual output have focused mainly on the relationship between written and oral. The classic work of Adolph Grohmann on The Islamic Book (Leipzig, 1929), and Johannes Pedersen's The Arabic Book remain

\footnotetext{
1 Johannes Pedersen, The Arabic Book (Copenhagen, 1946; Engl. transl., Princeton, 1984), 37.
} 
unequalled in many respects. Other works dedicated to more detailed aspects of the book as material entities have been produced later: notably, the works of Adam Gacek, The Arabic Manuscript Tradition (Leiden, 2001; plus Supplement, 2008) and Arabic Manuscripts: A Vademecum for Readers (Leiden, 2009) and Jonathan Bloom, Paper before Print. The History and Impact of Paper in the Islamic World (New York, 2001), among others, have greatly improved our understanding of the techniques of production of the Arabic book. ${ }^{2}$

If a systematic and exhaustive investigation into the production and circulation of the book has greatly progressed in recent years, a thorough analysis of the book as a communication means, and its role as a vehicle of dissemination of knowledge has been somehow under-researched. A statistical approach in the vein of the French Annales school, consisting in the study of the way books are produced and consumed, and the ideologies that can be traced throughout the process, has been seldom applied to the case of the Arabic book. A detailed statistical inquiry would be an enormous and time-consuming task, but this would be a promising line of research to shed new light on the spread and reception of books in the pre-modern period. Also still in its embryonic stages for the study of the Arabic book is the approach espoused by 'the history of books', a relatively new discipline at the intersection of diverse fields of research, including codicology, book production and circulation, history of reading and reception, textual criticism. This covers several areas, such as authorship, the transmission of knowledge, and the passage from oral to written culture, which is a point of tremendous significance for our purposes. History of books, in Darnton's words, aims at understanding 'how ideas were transmitted through print and how exposure to the printed word affected the thought and behaviour of mankind during the last five hundred years'. ${ }^{3}$ Since it has been identified as a worthwhile field of research, the history of printed books in general has greatly progressed. An adaptation of its patterns and methodology to the history of the manuscript book is not only possible, but also desirable given that this equally affected-albeit in different proportions - the transmission of ideas and the thought and behaviour of those who came into contact with manuscripts. Much more remains to be done in this field, especially for the Arabic manuscript books.

2 More bibliographic references are given in the dense pages of G. Endress, Handschriftenkunden, in W. Fischer (ed.), GAP, 1: Sprachwissenschaft (Wiesbaden 1982), $271 \mathrm{ff}$.

3 R. Darnton, 'What is the History of Books?', Daedalus 111/3 (1982), 65-83 (p. 65). 
In his introduction to The Book in the Islamic World, George Atyeh claimed that there was still 'a great need to look into the role of the book in the development of the Islamic world and its culture' and the history of the book 'not only as an artefact, but also in terms of intellectual content and physical properties, needs to be seriously explored'. ${ }^{4}$ Although our knowledge of some aspects of the Arabic book has been greatly expanded since then, it is nonetheless worthwhile responding to Atiyeh's implicit invitation and stimulate further reflection on some of the less well-investigated questions. Thus, The Book in Fact and Fiction in Pre-Modern Arabic Literature was conceived with a precise task in mind: to examine representations and images of the Arabic book in premodern period, both as reflected in the literary sources, and in the documentary evidence. It was intended as an operating tool to achieve a tentative definition of the concept of 'book', as a material and intellectual output, and of its role in cultural growth, as perceived by Arab-Muslim intellectuals of the pre-modern (and pre-print) period. The choice to restrict the investigation to this time-span was dictated by the enormous gravity of the manuscript tradition in the Middle East. Indeed, this tradition survived long after the introduction of printing, and coexisted with it (which, incidentally, resulted in a very long transition period). The desire to avoid the path of technical innovation, which would have involved questioning the issue of the 'electronic book', has also informed this choice of approach.

The potential issues invited in the call for papers included concepts of forgery and plagiarism; the circulation of forbidden, or non-canonical, books; books and the ways knowledge and intellectual exchange were transmitted; books as a means of dialogue between different cultures; cases of bibliophilia or bibliomania; motives driving to love, hate, accumulate or destroy books; literary representations of libraries, both public and private; the projection of the self upon the book as an intellectual product expressing some inner feeling; the dissemination of books and the roles of professionals; recommendations on handling books and writing materials; and the representation of, and appreciation for, professions involved in book-production and distribution.

Some of these issues found the favour of the authors and have been thoroughly investigated in single contributions. In other cases, they have been touched upon in articles whose contents overlap or intertwine. Other points that were raised in the call for papers remain unaddressed,

${ }^{4}$ G. Atyeh, The Book in the Islamic World. The Written Word and Communication in the Middle East (Washington D.C., 1995), xv. 
or have been addressed in a partial way, and call for further investigation. Indeed, I hope that they will be addressed in the future. In the process of assembling this volume, it soon became apparent that the two facets of the 'book', intended as a product of human intellectual and material activity, were more interrelated than expected. It was clear that an integrated approach, which combined the study of the material and intellectual sides of the Arabic book, could produce stimulating insights on the concept of book in addition to its impact on the development of intellectual life of the pre-modern Middle Eastern society. Some of the articles collected in this volume reflect the impossibility of sticking to a sharp separation between the two facets, and thus deal with the notion of 'book' as a global product involving physical and intellectual aspects in the same time.

A tentative synthesis of some points emerged in this volume of Journal of Arabic and Islamic Studies could be useful to draw an outline of the preliminary results of this investigation. A substantial question was the relationship between freedom and books. ${ }^{5}$ This has always been a delicate point, as demonstrated by the systematic practice of controlling books in dictatorships. Arguably, the fear of the written word has run through the history of the humanity. The fear of printing (as opposed to handwriting) that pervaded Europe immediately after Gutenberg's invention ${ }^{6}$ was a consequence of the uncontrolled and virtually infinite reproducibility of the texts in the printing age, which made knowledge more difficult to control, and undermined the authority of religious élites. Chirographic, Arabic-Muslim society was no exception, and its diffuse and long-lived wariness of the written word echoes, mutatis mutandis, this same sentiment.

A glaring example of this is represented by the case study of the debate on free and individual access to the texts aroused in the Sufi circles in the late fourteenth and early fifteenth centuries, and finely illustrated in this volume by Samuela Pagani. This also can be taken as an indication of reading-practice(s), a point tightly bound to the previous one, which has been raised at various junctures throughout this volume. The matter is especially relevant in a manuscript culture, in which reading out aloud was a primary practice in education and the canonical way of teaching and learning (and, in some respects, it still is). The

5 For illuminating reflections, see Luciano Canfora, Libro e libertà (Rome, 1994).

${ }^{6}$ In this respect, the friar who stubbornly stood up against the use of printing in Venice of the sixteenth century, on the basis that this would distort sacred texts and corrupt knowledge by making it available to illiterate people, recalls the positions of many scholars of the pre-modern Middle East. 
written word was intended to be read out, which explains why there was no need for punctuation marks to guide reading. Therefore, interpretation of the text made itself evident by virtue of pauses, segmentation, and the tone of the reader's voice. The significance of reading in the presence of a master, especially in the case of secret and/or religious knowledge, points to the importance of masters who could control access to the text, testify to true reading and, in the end, guarantee the 'correct' access to knowledge. This stands in sharp contrast with reading intended as an individual and silent practice, and its significance as a way of creating new meanings through the process of interpretation, a point underlined by the reception theory that describes it as an active process.

The cautiousness in approaching written texts-typical in educational circles, and all the more so in esoteric circles - is a topic touched on, at different levels, in articles dealing with the transmission and reception of texts. This mirrors the ambivalent attitude of Muslim intellectuals towards books, an issue which frequently emerges in this volume: books can be good or bad; dangerous or helpful; they can be widely circulated; hidden and even destroyed; they can be accumulated or sold and dispersed; they can be cherished or hated, or even feared. This sometimes implies dissociation between the imaginary and the factual: books of magic, for instance, were generally considered dangerous, but this did not prevent people from reproducing them nor hinder their circulation, as shown in Noah Gardiner's paper. This ambivalent attitude towards the object is no doubt grounded in wider opposition, more fiction than reality, between the two ways of transmission of knowledge: written and oral. The seminal works of Walter Ong and Jack Goody represent an essential point of departure for further inquiries. Nevertheless, they must be used with caution when applied to a 'writerly culture', a term befitting the 'graphomaniac tendency' that has characterised Arab-Islamic society in its long history.

The relationship between oral and written in Arabic sources has been carefully and widely investigated, and much more has been done in recent times. ${ }^{7}$ The antithesis of written and oral transmission is always present in the minds of Arab scholars and men of letters, and the issue of the reliability of written sources is a constant not only in the field of religious and legal studies, but also in more profane areas.

\footnotetext{
7 Not least by G. Schoeler, The Oral and the Written in Early Islam, ed., James E. Montgomery (London-New York, 2006); S. Toorawa, Ibn Abī Țāhir Tayfūr and Arabic Writerly Culture. A Ninth-Century Bookman in Baghdad (London-New York, 2005).
} 
The ambiguous relationships between these two alternative-and, in some measure, complementary-ways of transmitting knowledge has been addressed by almost all of the contributions, in tandem with the delicate balance between the need to depend on reliable and stable sources, and the wariness towards any forgery virtually implicit in any written source. In particular, the progressive reliance on written materials and the final acknowledgement of their status of trusted sources is thoroughly investigated in a case-study focusing on a specific literary genre, the 'profane love treatises', carefully explored in Monica BaldaTillier's article published herein.

This, and other contributions, also question, in different ways and in different respects, the concept of authorship and its various levels. The results are thought provoking and invite scholars to adopt cautious positions in accepting uncritically the attribution of some works in the huge corpus of the Arabic literature. The authority of many texts, whose reception and acceptance in the version(s) and form(s) are currently accepted, would probably not be so if submitted to thorough textual and philological scrutiny. This textual and authorial fluidity is also mirrored in the instability of the title, an issue that emerges patently in some papers: titles can change in the course of time; they can be transmitted orally; they can be attributed by the readers and not by the authors, and they can refer to works that consistently change their physiognomy as time goes by. Paradoxically, the fame of some personalities is tied to titles they never gave to their works, or to works they never conceived or published in the form(s) circulating later. As a matter of fact, it turned out that the concept of book as a well-defined textual unit, the final output of a single author to whom intellectual responsibility pertains, was probably much more fluid than that which we are accustomed to understand. While the existence of different levels of authorship relating to intervention and textual manipulation has long been acknowledged, the issue of a progressive construction of canonical texts has been much less investigated. The deep scrutiny of textual traditions carried out in a couple of contributions clearly demonstrates that, in some cases, by referring to ' $\mathrm{X}$ book of $\mathrm{X}$ author' we run the risk of making an inappropriate or ambivalent, if not false, statement. Through their casestudies, they convincingly show that two works circulating under the name of Ibn $\mathrm{Sa}^{\mathrm{c}} \mathrm{d}$, an historian of the formative period, and Ahmad alBūn̄i, the Sufi/'magician' of the seventh/thirteenth century are not-in their current forms and with their current titles - the original output of their putative authors. The results of their research point to a collective and long process of construction of 'canonical books', widely controlled 
by qualified readers (teachers, initiates, professionals) who participated in different ways in the partial or global dissemination of diverse formats and traditions of the original textual nucleus.

An interesting and ground-breaking question is the applicability of methodologies conceived for new disciplines to the specific field of Arabic studies. In the wider frame of the 'history of books' two points emerged as particularly promising: the 'communication circuit' as expounded by Robert Darnton, and the trend stressing the importance of paratexts in the perspective of a sociology of texts. The so-called communication circuit, conceived to investigate how printed books come into light and spread in society, is based on the holistic view of the book as a means of communication. It tries to assess how the book history 'disparate segments can be brought together within a single conceptual scheme' starting from the assumption that 'books belong to circuits of communication that operate in consistent patterns' ${ }^{8}$ The participants of the original pattern (author, publisher, printer, distributor, seller, reader) are obviously not all fitted to the study of manuscript culture. Nevertheless, this model can be readjusted to make it fit the reality of a manuscript culture. Indeed, Ahmad Nazir Atassi's contribution here aims precisely at testing the validity of such a model for the Arabic manuscript.

The 'participant-oriented' pattern of Darnton, criticised by some for its unbalanced approach that neglects the book as a product, was reoriented later into a more 'text oriented' model. In this vein some scholars focussed their attention on the significance of paratexts, i.e. the liminal elements that determine and reveal how the text is perceived by its readers. ${ }^{9}$ Being located at the fringe, paratexts constitute a transitional zone where the interaction between the text and its public can take shape. This issue deserves careful investigation since it can offer promising insights for the study of the Arabic manuscript books. This could be made on condition that the typological range of the texts originally covered by the hypernym 'paratext' is varied and adapted to its different historical settings. For instance, the paratext can also be intended as the trace left by the 'editors'/publishers of books (copyists), the 'professional' readers (scholars involved in the reception and dissemination of the texts contained in the books) and 'simple readers', such as those who used books for their private purposes adding notes and glosses, thus forming a 'bridge' between readers. Iğāzas, reader's

\footnotetext{
8 Darnton, 'What is the History of Books?', 75 and 81.

9 See, for example, the work of Gérard Genette, Seuils (Paris, 1987).
} 
comments, corrections, and glosses can thus contribute to the reception and circulation of the books. The significance of paratexts is the issue addressed in Noah Gardiner's article that thoroughly investigates them (especially titles and notes) in the view of determining the interaction between text, readers and the textual transmission of authoritative works. This constitutes a stimulating hint at the circulation of a specific text, but also at the intellectual representations involved in the dissemination and the reception of a certain kind of knowledge.

The interdependence between the cultural and social significance of the text on the one hand, and its material shape on the other is precisely what defines the book as a cultural object: no text can circulate in a 'pure' form, i.e. without any material support to make it readable. The particular significance of the materiality of books points to the need of a thorough and intense research on the several aspects of books production and the role that the diverse craftsmen played in it. Being placed at the intersection of intellectual work (collation, proofreading) and material activity (copying, binding), and often involving a close connection with sacred and canonical texts, the status and role of the professionals of the book market is crucial for a better understanding of the book as a communication tool. Many specialisms were involved in the book business: the calligrapher (hatțata $)$, the cutter of paper $\left(q \bar{a} t i^{i}\right)$, the gilder (mudahhib), and the bookbinder (muğallid). Among them 'the immense importance of the warrāq to the world of books'10 must be emphasised. The warrāq probably had the same role that the printer and the bookseller (and sometimes the publisher) have in Darnton's 'communication circuit'. To know more about the professionals involved in book production we can turn to the material evidence of the physical item itself. This is no doubt a precious and first-hand contribution in terms of techniques of production (treatment of the paper, techniques of copying and bookbinding), but leaves aside the evaluation of their daily activity, their role in society, and the status they had in the eyes of their contemporaries. For that we must turn to the witness of the sources that - directly or indirectly - tell of the participants' relationship to the 'communication circuit'. In this respect, the treatises that the jurists wrote to regulate in detail the life of the umma are valuable sources. When explicit interdictions come into play, we must infer that they are grounded in real practices that the jurists felt as reprehensible. This kind of literature thus represents first-hand evidence of the intellectuals' attitude towards the book, both as a vehicle of transmission of

10 Pedersen, op. cit., 52. 
knowledge and as a physical item. This topic has also been explored in this volume with a particular focus on the Mamlūk era. The greater attention that Mamlūk jurists dedicated to the book corresponds to the remarkable growth and particular vitality in the book market which characterised this period, something that, from different points of views, emerges from Balda-Tillier's article dealing with the status of books as reliable sources or with the remarkable growth in the output of manuscripts.

The wealth of books in that period is reflected in many historical sources that describe remarkable libraries and book collections in laudatory terms. Throughout the history of the 'graphomaniac' ArabMuslim culture, books were appreciated both as repositories of knowledge and as material objects, amassed for their aesthetic value and for their utility to scholars, giving birth to huge collections. Our knowledge of the Arab-Muslim libraries has been enriched by some seminal studies, such as Quatremère's very early pioneering study; ${ }^{11}$ later works by Pinto, ${ }^{12}$ Eche, ${ }^{13}$ Touati ${ }^{14}$ et al., and most recently by Hirschler. ${ }^{15}$ All in all, there is still much to know about libraries, and in particular private libraries and collections. Their organisation; systems of cataloguing; the location of volumes on the shelves; the role and activity of librarians, copyists, bookbinders and others involved in the maintenance and running of the library, doubtless deserve deeper investigation. Literary and historical sources do not usually offer meaningful insights in the everyday activities of libraries. Rather, they tend towards cursory references to some prominent scholars' collections or deal with libraries in connection with dramatic circumstances such as wars and riots that provoked their destruction.

The representation of libraries, both public and private, was among the points to be investigated. Two articles here elucidate these points. Through the lens of literary sources, the first outlines a picture of a scholar's private library also known for his bibliophilia; while the latter delves into some problematic aspects of cataloguing on the evidence

11 É. Quatremère, Mémoire sur le goût des livres chez les orientaux (Paris, 1838).

12 O. Pinto, 'Le biblioteche degli arabi nell'età degli Abbasidi', La Bibliofilia 30 (1928), 139-65; Eng. transl., 'The libraries of the Arabs during the time of the Abbasids', Islamic Culture, 3 (1929), 210-43.

13 Y. Eche, Les Bibliothèques arabes publiques et semi-publiques en Mésopotamie, en Syrie et en Égypte au Moyen âge (Damascus, 1967).

$14 \mathrm{H}$. Touati, L'Armoire à sagesse. Bibliothèques et collections en Islam (Paris 2003).

15 K. Hirschler, The Written Word in the Medieval Arabic Lands: A Social and Cultural History of Reading Practices (Edinburgh, 2012). 
from first-hand sources. These studies also raise further questions, related to the exact interpretation of terms. To recall the title of an article by Franz Rosenthal, we can say that 'of using many words to refer to books there is no end'. ${ }^{16}$ Clearly the term kitāb is not co-extensive with 'book' and remains somehow ambiguous, considering that in its primary meaning it referred to the result of the act of writing and could thus identify a letter, a charter, a note, or anything fixed by writing. Depending on the type of sources consulted concerning the discipline, the historical period and the cultural milieu, many other terms can be found to identify the item 'book'. The result is that it is sometimes difficult to understand to which physical entity the terms exactly refer, and words like daftar, muğallad, ğuz ${ }^{\nu}$, muṣhaf and so on, transmit different conceptual and physical entities.

Contemporary readers are seldom certain that the object they visualise corresponds to what the author had in mind and to what the pre-modern reader understood. Even if nowadays scholars can rely on valuable reference works, they could still feel a certain unease in interpreting the terms which should convey a precise mental image and thus depict a precise physical item. But even in the past conceptual ambiguities were difficult to avoid, for instance when the need of cataloguing prompted librarians to decide whether a certain physical item had to be ascribed to a conceptual category or another. Further contributions exploring the conceptual boundaries of the terms referring to the book in relation with well-defined historical periods, cultural milieux and disciplinary fields would no doubt be desirable.

The richness of the range of topics, periods and disciplines covered by the authors who generously participated in this enterprise, shedding light on the Arabic book in fact and fiction from diverse points of views, could only be partially represented by a quick and analytical glance at the individual contributions. The first article, by Peter Webb, focuses on the ideas of the famous polymath and bibliophile al-Ğāhiz, and explores his conception of book as a vehicle to transmit knowledge, in connection with the intellectual heritage foreign to the purely Arabic tradition. This encompasses some intertwined debates about the status of books as repositories of authoritative knowledge, the position of Arab/non-Arab in the light of the Šu îbiyya movement, along with the position of the intellectual heritage of pre-Islamic 'civilisations'. The evaluation of three key notions (book, knowledge, ethnicity) taken together sheds new light

16 F. Rosenthal, “'Of Making Many Books There Is No End”: The Classical Muslim View', in Atiyeh, The Book in the Islamic World, 33-56. 
on aspects of al-Ğāhiz's — sometimes ambivalent—praise of books and writing against the background of the growing integration of multiple cultural traditions into Muslim 'civilisation'. The conclusions point to a re-evaluation of al-Ǧāhiz's great respect for books, which was, actually a respect for 'Arabic' books - and, perhaps, notably his own. The 'ideal book' extolled by this polymath turns out to be a sample of the typically Arabic eloquence and stylistic elegance (bayān). This definitely puts it out of reach of competition with the literary outputs of other cultural traditions, and permits to ascertain its superiority in the name of the superiority of the Arabic language.

The article by Ahmad Nazir Atassi explores, through a sample study, the validity and adaptability of the 'communication circuit' elaborated by Darnton to the pre-print tradition in an Arab-Islamic context. In particular, Atassi elaborates a methodological framework to study the mechanics of survival of medieval Islamic books, which involves adapting, reducing or replacing some segments of the circuit. A focal point in this is the assessment of the role played by books (as material objects) in their trajectory in private and public spaces. In this respect, the production/reproduction and circulation of a book in a specific social circuit can act as a clue to a better understanding of how and where knowledge was disseminated, or hint at the perceived value of 'canonical' books. The inquiry focuses on the history of the earliest extant biographical dictionaries, Ibn Sa ${ }^{c}$ 's (d. 230/845) Kitāb alTabaqāt al-kabìr, which, in its current textual form, turns out to be a product of the seventh/thirteenth century. The analysis of the book's transmitters and their historical contexts, based on as ānìd, helps to trace the survival of this text's multiple recensions and their geographical diffusion. The issues raised by this article are manifold: the tension between the single item and the canon; the relationship between the whole textual unit and its segmentation (and the unequal circulation of these), as well as the unstable concept of authorship, and multiplicity and 'natural selection' of different recensions.

The process of construction of 'canonical' text books, which highlights a type of 'shared authorship' of the participants (teachers, students, readers and so on) and the fluid nature of canonical texts are also issues touched in the following article by Noah Gardiner. This article focuses on the transmission of the works attributed to Ahmad alBūnī, and consists of an extensive survey of a huge manuscript corpus. The output of the survey is an overview of the major works of the medieval Būnian corpus, the assessment of their authenticity and, as a side product, the acquisition of new information on al-Būnī's life. 
Gardiner's conclusions also point to a new assessment of the authorship and dating of the work to which al-Būnī owe his fame, $\check{S} a m s$ al-ma ${ }^{c} \bar{a}$ rif al-kubrä, which, in the form of it that we have, turns out to be a product of the early eleventh/seventeenth century. From a methodological viewpoint, the perusal of the texts coupled with an extremely accurate study of paratexts (transmission certificates and ownership notices) seems very promising for an appropriate re-evaluation of the texts and of their circulation. A delicate question raised by this detailed case study is the unreliability of some printed editions for the reconstruction of the intellectual heritage of Islam, in particular in the field of esoteric disciplines.

The path of having recourse to the perusal of esoteric texts as a clue to the image of the Arabic book is also shared by Samuela Pagani, who proposes a case study focused on the educational function of Sufi books which took place at the end of the fourteenth century and beginning of the fifteenth. This alludes to a disputed question, the legitimacy of having recourse in the educational process to written textbooks as substitutes for masters, an issue that went well beyond the borders of esoteric circles, as attested by Ibn Haldūn's intervention on the topic. This heated debate is also taken as an indicator of the growing importance of private reading in intellectual life and educational processes, an issue that ultimately refers back to the unending tension between orality and writing. The subjects treated in this article (the relationship between free access to knowledge and its control, the tension between private reading and the tendency towards innovation) deserve even further investigation in other periods and disciplines, which would cast new light on the development of relationships between authority and knowledge in Islamic cultural history.

The attitude of intellectuals towards their sources is the topic of Monica Balda-Tillier's contribution. It explores the tension between the use of written and oral sources and the shifting attitude towards acceptability as reliable authorities. Taking as a point of departure thirteen love treatises spanning from the fourth/tenth to the eleventh/seventeenth centuries, Balda-Tillier carries out an accurate survey of the techniques of quotations. The results demonstrate that the use of the traditional isna $\bar{d}$, which boil down to a list of oral sources, tends to disappear to the advantage of citations of book-titles. At an individual level, to have recourse to written sources plausibly has to do with the assertion of a certain type of authorship, which consists of choosing and reshaping earlier materials. Put in its historical context, this shows a shifting attitude towards writing as a reliable way of 
transmitting knowledge. It is not fortuitous that the turning point in this process proves to be a work of the Mamlūk period: the treatise of Mugultạy (d. 762/1361), who lived in Cairo in a time when writing and written texts played a key role in education. The hypothesis put forward in this case study sketches out the interest of extending quantitative investigation to other 'genres' of Arabic literary output. This also seems a promising line of research to ascertain if there is a common turning point in the 'never-ending affair' of the tension between writing and orality in the intellectual history of the region.

The increasing confidence in books that seems to emerge in this period is parallel to the contemporary vitality of the book market, a side effect of the bookishness often attested in the sources for the Mamlūk period. But bibliophilia and the love of books seem to be a very typical feature of Arab-Muslim cultural history as a whole. References to cases of bibliophilia, reports of cases of exaggerate love for books, information about collections of books are scattered in the literary sources of all the periods. The paper by Letizia Osti investigates the image of a private library in the fourth/tenth century focusing on the quality and physical arrangement of books contained therein. The collection of Abū Bakr alȘūlī, his love for books, and his reliance on writing as a source of knowledge (something which is severely censured in some biographical reports on him), are portrayed on the basis of the representations found in both contemporary and later sources. This presentation offers insights into the organisation of scholars' private libraries, even more stimulating if we consider the renown of al-Ṣūin as a passionate book-collector but also to his reputation as a scholar who was too dependent on written sources. Osti's brief paper calls for further investigation on private libraries both as a contribution to a better knowledge of their contents and organisation, and their literary representations as symbols of intellectual and social phenomena: bibliophilia, the relationship between books and knowledge, the circulation of books in the scholars' circles, the use of books as a status symbol and so on.

The study of libraries and books collections can also raise theoretical implications, like the definition of the concept of 'book', a challenging issue treated by Konrad Hirschler in his paper. The detailed investigation of a seventh/thirteenth-century library catalogue from Damascus shows that this concept in the Middle Period was far from being clear-cut, something that is also mirrored in the Formative Period. The perusal of the catalogue section dedicated to $m a g \bar{g} a m \bar{l}^{c}$ (miscellaneous volumes) and to the arrangement of the single items shows that the person in charge of the cataloguing had recourse to two different definitions of 'book'. The 
first is based on its immaterial aspects and corresponds to a textual unit. The second responds more to its material shape. This ambivalence, while showing the intricacy of finding a unique clear-cut operating definition, also hints at the intertwined nature of both material and immaterial aspects of books. Hirschler's contribution thus has a double interest: theoretical on the one side, and more practical on the other. It presents an unusual and rarely considered viewpoint on books: that of the 'librarian', who clearly had a different perspective from authors or readers, and whose role had probably to be based on perceived category distinctions. This also offers incisive views on the practical matter of arrangement that was faced in libraries, and on the role that professionals could have in handling and treating the books.

Related to the role of professionals of the book business is also the following essay by Giovanni Canova, who explores key aspects of the production and the handling of books through the eyes of the jurists and notably Ibn al-Ḥāğğg, Tāğ al-Dīn al-Subkī and Ibn Ğamāa a. The article consists of a critical selection and commentary of texts dating to the eighth/fourteenth century, a period in which jurists and ${ }^{\mathrm{c}} u l a m \bar{a}^{\mathrm{j}}$ showed a particular interest in the activities involved in book production. They explored all the aspects of the book-business, including practical instructions on how protect the volumes during consultation, how to put them in the stacks, and how to copy them, concerns which complement more general considerations on 'professional ethics'. Nor did they neglect to regulate craftsmen's everyday activities, giving detailed advice to the bookseller ( $k u t u b \bar{l}$ or, more frequently, warrāq), the copyist (nāsih/nassäh), the bookbinder (muğallid), and the broker/bookseller (dalla $l)$. The strong ethical slant of these treatises is particularly evident when the ${ }^{\mathrm{c}}$ ulam $\bar{a}^{\mathrm{J}}$ urged the book artisans to act by following a strict Islamic moral code, on the ground of precepts such as the concept of mitālor 'pattern of behavior'; adab 'correct way to act,' and niyya or 'good purpose'. Their remarks no doubt constitute a significant- though indirect-contribution to our knowledge of the book market in the Mamlūk period. Along with documentary sources, such as waqf legal documents, they can help illuminate the role of 'professionals' involved in the processes of book production and circulation.

The multiple issues raised in this themed volume show the intricacies of the study of the pre-modern Arabic book in all its aspects, at a time when the traditional printed book meets new challenges, exactly like the manuscript books had to meet the challenges of printing - although admittedly in a less dramatic way. Indeed, the essays contained in this 
(paradoxically) electronic volume are a witness to the great significance of the Arabic book in the intellectual history of the pre-modern period.

Finally, I wish to express my gratitude to those who responded to the call for papers and met the challenge of taking our knowledge of the Arabic book a step forward in a, hopefully, significant way. I also feel that I must express my gratitude to the editor of the Journal of Arabic and Islamic Studies, Alex Metcalfe, who accepted the idea of dedicating a volume of the journal to this theme, patiently edited the texts and helped us all keep to the deadlines. Working with him and with the colleagues who contributed (and who, presumably, share my love of books) has been a very enriching and extremely instructive experience for which I owe them my warmest gratitude. 